\title{
BMJ Open Risk factors associated with the coexistence of stunting, underweight, and wasting in children under 5 from 31 sub-Saharan African countries
}

\author{
Iddrisu Amadu (D) , 1,2,3 Abdul-Aziz Seidu (D) , 4,5,6 Eric Duku (D) , 1,2 \\ James Boadu Frimpong (i) ,7 John Elvis Hagan Jnr. (1) , ${ }^{7,8}$ Richard Gyan Aboagye, ${ }^{9}$ \\ Belinda Ampah, ${ }^{10}$ Collins Adu, ${ }^{11}$ Bright Opoku Ahinkorah (D) ${ }^{12}$
}

To cite: Amadu I, Seidu A-A, Duku E, et al. Risk factors associated with the coexistence of stunting, underweight, and wasting in children under 5 from 31 sub-Saharan African countries. BMJ Open 2021;11:e052267. doi:10.1136/ bmjopen-2021-052267

- Prepublication history and additional supplemental material for this paper are available online. To view these files, please visit the journal online (http://dx.doi.org/10.1136/ bmjopen-2021-052267)

Received 20 April 2021 Accepted 18 November 2021

Deck for updates

(c) Author(s) (or their employer(s)) 2021. Re-use permitted under CC BY-NC. No commercial re-use. See rights and permissions. Published by BMJ.

For numbered affiliations see end of article.

Correspondence to Abdul-Aziz Seidu; abdul-aziz.seidu@stu.ucc. edu.gh

\section{ABSTRACT}

Objective This study investigated the risk factors associated with the coexistence of stunting, underweight, and wasting among children under age 5 in sub-Saharan Africa (SSA).

Design Data of 127,487 under- 5 children from 31 countries in SSA were pooled from the Demographic and Health Surveys collected between 2010 and 2019. We examined the risk of coexistence of stunting, underweight, and wasting using multinomial logistic regression models. The results were presented using relative risk ratios (RRR) with corresponding confidence intervals (Cls).

Setting Thirty-one sub-Saharan African countries. Participants Children under age 5.

Outcome measures The outcome variables were three child anthropometrics: stunting (height-for-age z-scores); underweight (weight-for-age z-scores) and wasting (weight-for-height z-scores).

Results The prevalence of coexistence of stunting, underweight, and wasting varied across countries, with the highest $(12.14 \%)$ and lowest $(0.58 \%)$ prevalences of coexistence of stunting, underweight and wasting in Benin and Gambia respectively. The risk of coexistence of the three indicators of undernutrition was higher among children aged 1 year (RRR=3.714; $95 \% \mathrm{Cl} 3.319$ to 4.156 ) compared with those aged 0 . The risk of coexistence of the three dimensions was lower among female children ( $R R R=0.468$ $95 \% \mathrm{Cl} 0.420$ to 0.51 ), but higher for those with small size at birth ( $R R R=3.818 ; \mathrm{Cl} 3.383$ to 4.308), those whose mothers had no education (RRR $=3.291 ; 95 \% \mathrm{Cl} 1.961$ to 5.522 ), not working (RRR=1.195; $95 \% \mathrm{Cl} 1.086$ to 1.314 ), had no antenatal visits during pregnancy (RRR $=1.364 ; 95 \% \mathrm{Cl} 1.20$ to 1.541), children delivered at home ( $\mathrm{RRR}=1.372 ; \mathrm{Cl} 1.232$ to 1.529 ), those from poor households ( $R R R=1.408 ; 95 \% \mathrm{Cl}$ 1.235 to 1.605$)$, those whose mothers had no access to media (RRR=1.255; 95\% Cl 1.144 to 1.377 ) and living in households with an unimproved toilet facility $(\mathrm{RRR}=1.158$; $95 \%$ Cl 1.032 to 1.300 ).

Conclusions Findings suggest the urgent need for consideration of the coexistence of stunting, wasting and underweight among under- 5 children in policy design and programming of interventions to eradicate child malnutrition in SSA. In the short-term, nationallevel policies and interventions need to be well tailored considering the compositional characteristics.

\section{Strengths and limitations of this study}

- The use of relatively large nationally representative data of under- 5 children from 31 countries in SSA is the main strength of the study.

- We also employed rigorous statistical analytical techniques to analyse the data.

- A broad range of potential risk factors at various levels were considered in our analysis.

Despite this, the surveys were conducted in different years which may affect comparisons.

- Also, the Demographic Health Survey employs cross-sectional designs which restrict causality on the noted outcomes.

- Self-reported variables used are susceptible to biases from recall and other social desirability issues.

\section{INTRODUCTION}

Undernutrition among children under 5 years remains a major public health problem across many low-income and middle-income countries. ${ }^{1-3}$ Factors such as insufficient food intake, diarrhoea, recurring infections, poor sanitation practices, and low parental education have been identified as significant contributors to the high prevalence of undernutrition during childhood. ${ }^{145}$ Despite the numerous interventions rolled out to address childhood undernutrition especially in subSaharan Africa (SSA) where the phenomenon is quite pervasive, the progress seems to be insignificant. ${ }^{67}$ For example, a study reported that child undernutrition accounted for nearly half $(45 \%)$ of the child mortality rate in low-income and middle-income countries. ${ }^{8}$ Aside from that, it was reported in 2018 that about 149 and 49 million children under age 5 were stunted and wasted, respectively. ${ }^{9}$

Three main indicators that are often used to measure undernutrition are underweight or low weight for age, stunting or low height for 
age, and wasting or low weight for height. ${ }^{210-12}$ Among the three indicators of undernutrition, stunting has been identified as the condition with the highest prevalence among under 5 children in low-and middle-income countries. ${ }^{23}$ Even though the prevalence of stunting in SSA is decreasing, it is worth noting that it is still above $30 \%{ }^{13}$ which is undeniably high. Research also indicates that the country-specific prevalence of stunting, underweight and wasting is still high. ${ }^{23}$ For instance, in Ethiopia, the prevalence of wasting and stunting were $10 \%$ and $38 \%$, respectively ${ }^{14}$. Additionally, the prevalence of stunting, underweight and wasting among children in South Africa were $35.8 \%, 20.5 \%$ and $17.2 \%{ }^{3}$ Likewise, Anin et $\mathrm{al}^{2}$ reported $33.2 \%, 14.1 \%, 27 \%$ and $2.6 \%$ of prevalence in stunting, wasting, underweight, and overweight respectively among infants (6-23 months) across Northern Ghana.

Previous studies on the compositional and contextual risk factors associated with either stunting, underweight or wasting among children under 5 years found the age of a child, sex of the child, child's size at birth, mother's age during childbirth, mother's educational level, birth order, place of residence and mother's body mass index (BMI) as associated factors. ${ }^{1-3} 1516$ Other studies also found a significant linkage between household wealth quintile and maternal short stature, and nutritional status of children under $5 .{ }^{17}{ }^{18}$ Regarding the sex of a child, for example, female children were found to be less likely to suffer from stunting compared with males. ${ }^{13}$

Apart from studies that have examined the factors associated with either stunting, underweight and wasting, some scholars have begun looking at predictors of the coexistence of more than one of the indicators of undernutrition. A study in 84 countries that examined the prevalence and predictors of coexistence of stunting and wasting found sex and age of children as significant predictors. ${ }^{19}$ Other studies in Ghana ${ }^{20}$ and India ${ }^{21}$ also examined the coexistence of stunting, underweight and wasting and found birth interval, birth weight, dietary diversity, place of delivery, wealth index, mother's BMI, mother's educational level, and partners' educational level as associated factors. The need to examine the coexistence of stunting, underweight, and wasting is important because not much work has been done on that subject and hence children who suffer simultaneous impacts of stunting, underweight, and wasting are less likely to be reached by undernutrition prevention programmes, especially in SSA. For instance, studies indicate that despite the evidence that wasting and stunting are global public health problems that frequently coexist, they are usually separated in terms of policy, guidance, programming, and financing. ${ }^{22}$ This creates a gap in the literature that needs to be filled. Despite the potentially heightened consequences of undernutrition on the health and well-being of children under 5 in SSA, studies utilising current, and nationally representative data to investigate the risk factors associated with the coexistence of stunting, underweight, and wasting among this age group are sparse. Studies presenting empirical analyses of the coexistence of these three indicators of child undernutrition in SSA are absent in extant literature making it

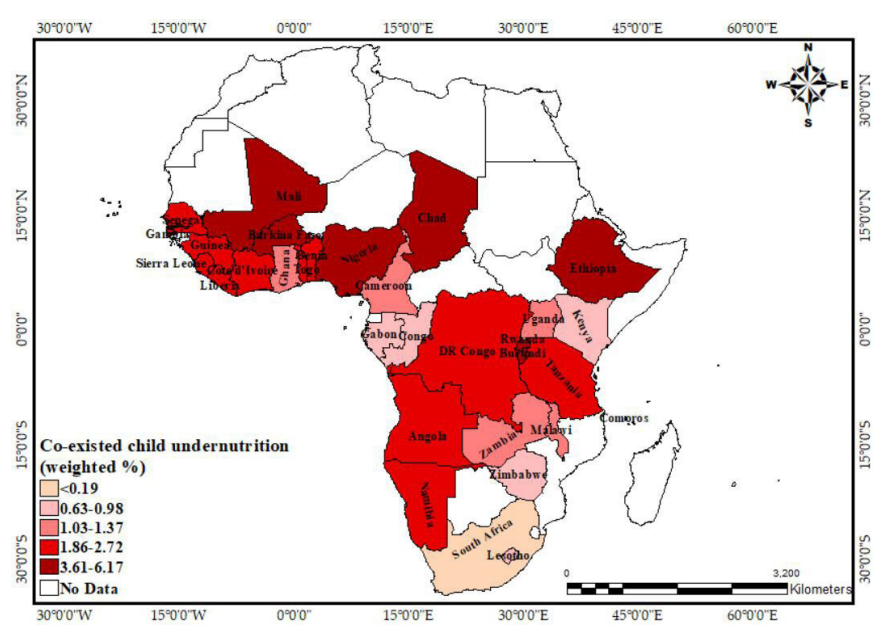

Figure 1 Percentage distribution of coexistence of stunting, underweight and wasting in children from the 31 study countries in SSA.

difficult for policymakers and nutritional experts to provide up-to-date trends with appropriate strategies to curb the situation in the subregion. This research lag presents a void in extant literature which this study seeks to fill. The aim of this study was to examine the risk factors of the coexistence of stunting, underweight, and wasting among children under age 5 in SSA using data from the Demographic and Health Survey (DHS) conducted in 31 countries between 2010 and 2019. The findings of the study could contribute to the formulation of policies and interventions to respond to the nutritional needs of children under 5 years and also suggest pragmatic ways of reducing undernutrition among children in the sub-region.

\section{METHODS}

\section{Data source}

The dataset included 127, 487 children under the age of 5 years from 31 countries in SSA (figure 1) were pooled from the most current DHS conducted between 2010 and 2019 (online supplemental appendix 1). Specifically, the data were pooled from the children's files in each of the countries. The DHS Programme has conducted over 400 surveys in over 90 low-and middle-income countries around the world since 1984 every 5 years. ${ }^{23}$ The programme implements cross-sectional surveys to gather nationally representative data, analyse and disseminate accurate information on important demographic and health indicators spanning population, nutrition and diseases. For all surveys, standardised protocols designed for each target group including children, women and men at the household level are employed to allow for cross-national comparisons. Stratified two-stage sampling involves first, the listing of enumeration areas and selection of clusters, and then a random selection of households in each cluster. The detailed sampling method can be found in a previous study. ${ }^{24}$ The data set is freely available for download at: https://dhsprogramcom/data/ available-datasetscfm. ${ }^{25}$ The Strengthening Reporting of 
Observational Studies in Epidemiology guidelines were followed in writing the manuscript. ${ }^{26}$

\section{Study variables}

\section{Outcome variable}

The outcome variable considered in this study is derived from three child anthropometric variables including stunting (height-for-age z-scores); underweight (weightfor-age z-scores) and wasting (weight-for-height z-scores). The DHS specifies categorisation for each of these variables following the WHO child growth standard. Each of the three variables were coded into ' 0 ' for 'Normal' and ' 1 ' for 'Stunting', 'underweight' and 'Wasting', respectively.

These three variables were then added to generate the outcome variable 'Coexisted undernutrition' with scores (discrete) ranging from 0 to 3 where 0 implies 'Normal', that is, children with none of the three conditions; 1 implies 'Single burden', that is, the child suffers from one of the three conditions; 2 indicates that a child suffers from 'Two burdens' out of the three; and 3 shows 'Coexisted', that is, the child suffers from all three conditions of undernutrition. For parsimony, children who suffered from 'Single burden' and those who suffered from 'Two burdens' were added resulting in the variable 'Coexisted undernutrition' with three response categories: $0=$ normal; $1=$ one or two burdens and $3=$ coexisted.

\section{Independent variables}

Several risk factors spanning compositional to contextual factors have been associated with child undernutrition. The relevant biosocial characteristics and sociocultural factors related to the child, mother, household head and the household together form compositional factors. ${ }^{27} 28$ Factors that describe location or 'place-based' variables are contextual factors. ${ }^{20} 272930$ The relevant compositional factors considered include the age of the child; sex of the child; birth order of child; perceived size at birth; mother's age; educational attainment; working status; antenatal visits during pregnancy; postnatal check within 2 months and place of delivery. At the household level, relevant variables included are the wealth status; the age of household head; sex of household head (male and female); access to electricity and access to media which was derived from the three variables 'access to television', 'radio' and 'newspaper'. Household basic needs include the type of toilet facility (recoded into 'improved' and unimproved'; ${ }^{29}$ source of drinking water (recoded as 'improved' and 'unimproved') ${ }^{29}$ and type of household cooking fuel (recoded into 'clean' and 'unclean') ${ }^{29} 31$ are also considered. The contextual factors considered are urbanicity and the country of origin of the participant.

\section{Data analyses}

The statistical analysis of the data was performed using the Stata SE software V.14.2. The 'svyset' command was first used to declare the data as survey data to prevent the potential effects of the complex sampling techniques

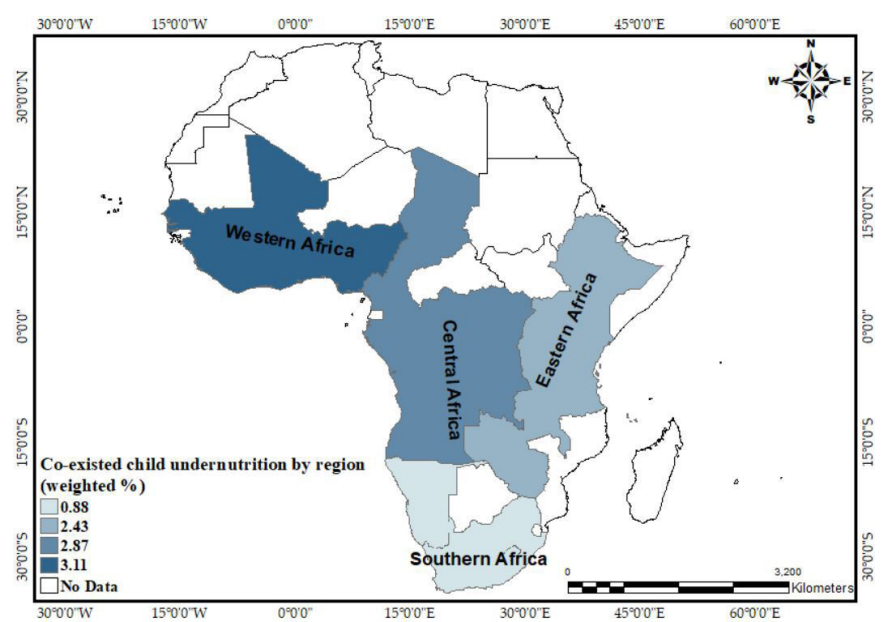

Figure 2 Percentage distribution of coexistence of stunting, underweight and wasting in children by regions of SSA.

on the analyses. The sample weight variable in the DHS was used to provide weighted samples in the analyses. To understand the distributions of the variables, the data were summarised and presented in tables using descriptive statistics (frequencies, weighted percentages and 95\% CIs of percentages). We further integrated the data into a Geographic Information System environment and presented the distribution of key variables across the study countries and geographic regions in map images (figures 1 and 2). This approach enhances the visualisation of the data and understanding of the context of the study. The associations between the coexistence of undernutrition and each of the risk factors considered were assessed using the $\chi^{2}$ test of independence, with results presented in a contingency table. The risk factors as independent variables were then subjected to collinearity diagnosis tests, including variance inflation factors (VIF), square VIF, tolerance and $\mathrm{R}^{2}$. This was done to ascertain whether the independent variables were actually 'independent', that is, are not correlated with one another and will not share variance in the outcome variable. Results from the multicollinearity diagnoses test (see online supplemental appendix 2) show that the variables were not correlated (mean $\mathrm{VIF}=1.26$; maximum $\mathrm{VIF}=1.71$; minimum VIF=1.02). To determine the risk factors associated with the coexistence of undernutrition, a multinomial regression model was implemented. All statistical tests were conducted at $\mathrm{p}<0.05$.

\section{Patient and public involvement}

Patients and the public were not involved in the design and conduct of this research

\section{RESULTS}

\section{Distribution of sample characteristics}

The study included a total of 127, 487 under-5 children. It was found that most $(30.87 \%)$ of the children were less than a year (table 1). With regard to sex, both males and females constituted approximately half of the sample. A 
Table 1 Distribution of the relevant variables and characteristics of under-5 children in SSA

\begin{tabular}{|c|c|c|c|}
\hline Variable & $\%$ & Variable & $\%$ \\
\hline \multicolumn{2}{|l|}{ Age of child } & \multicolumn{2}{|l|}{ Urbanicity } \\
\hline 0 & 30.87 & Urban & 33.21 \\
\hline 1 & 28.42 & Rural & 66.79 \\
\hline 2 & 20.22 & \multicolumn{2}{|l|}{ Place of delivery } \\
\hline 3 & 12.40 & Home & 31.33 \\
\hline 4 & 8.09 & Health facility & 67.51 \\
\hline \multicolumn{2}{|l|}{ Sex of child } & Other & 1.16 \\
\hline Male & 50.47 & \multicolumn{2}{|l|}{ Wealth status } \\
\hline Female & 49.53 & Poor & 42.41 \\
\hline \multicolumn{2}{|l|}{ Birth order } & Middle & 20.28 \\
\hline 1 & 19.52 & Rich & 37.31 \\
\hline $2-4$ & 48.09 & \multicolumn{2}{|c|}{ Age of household head } \\
\hline 5 and above & 32.39 & Young-adults & 43.08 \\
\hline \multicolumn{2}{|c|}{ Perceived size at birth } & Middle-aged adults & 43.76 \\
\hline Large & 33.71 & Old-aged adults & 13.16 \\
\hline Average & 49.74 & \multicolumn{2}{|c|}{ Sex of household head } \\
\hline Small & 16.54 & Male & 79.77 \\
\hline \multicolumn{2}{|c|}{ Mother's characteristics } & Female & 20.23 \\
\hline \multicolumn{2}{|l|}{ Maternal age } & \multicolumn{2}{|l|}{ Access to electricity } \\
\hline $15-19$ & 7.13 & No & 69.20 \\
\hline $20-49$ & 92.87 & Yes & 30.80 \\
\hline
\end{tabular}

\section{Educational attainment}

\begin{tabular}{|c|c|c|c|}
\hline $\begin{array}{l}\text { No formal } \\
\text { education }\end{array}$ & 41.82 & \multicolumn{2}{|c|}{ Type of toilet facility } \\
\hline Primary & 31.26 & Improved & 42.47 \\
\hline Secondary & 23.82 & Unimproved & 57.53 \\
\hline Higher & 3.10 & \multicolumn{2}{|c|}{ Source of drinking water } \\
\hline \multicolumn{2}{|c|}{ Working status } & Improved & 65.63 \\
\hline No & 35.49 & Unimproved & 34.37 \\
\hline Yes & 64.51 & \multicolumn{2}{|c|}{ Type of cooking fuel } \\
\hline \multicolumn{2}{|c|}{$\begin{array}{l}\text { Antenatal visits during } \\
\text { pregnancy }\end{array}$} & Clean & 89.76 \\
\hline No & 10.76 & Unclean & 10.24 \\
\hline Yes & 89.24 & \multicolumn{2}{|c|}{ Geographic region } \\
\hline \multicolumn{2}{|c|}{ Postnatal check within 2 months } & Western & 41.78 \\
\hline No & 58.49 & Eastern & 32.84 \\
\hline Yes & 41.51 & Central & 20.08 \\
\hline \multicolumn{2}{|c|}{$\begin{array}{l}\text { Access to media (tv/radio/ } \\
\text { newspaper) }\end{array}$} & South Africa & 5.30 \\
\hline Yes & 35.33 & & \\
\hline No & 64.67 & $(n=127487)$ & \\
\hline
\end{tabular}

SSA, sub-Saharan Africa.

majority of the children (92.87\%) were born to mothers aged between 20 and 49 years, while only $7.13 \%$ were born to mothers aged 15-19years. In terms of education, most (41.82\%) of the children were born to mothers with no formal education. Only $3.10 \%$ of the children were born to a mother with a higher level of educational attainment. Furthermore, $42.41 \%$ of the children were born in poor households, while $37.31 \%$ were born in rich households. More than half $(57.53 \%)$ of the children lived in a household with unimproved toilet facilities. However, most $(65.63 \%)$ of the children lived in households with access to improved drinking water sources. Similarly, a majority $(89.76 \%)$ of the children lived in households using clean cooking fuel (table 1).

As shown in online supplemental appendix 2, the prevalence of coexistence of stunting, underweight and underweight varied across countries and subregions, with the highest and lowest prevalence of coexistence of stunting, underweight and wasting as Rwanda $(6.17 \%)$ and South Africa $(0.18 \%)$, respectively (figure 1$)$. In terms of subregion, the highest prevalence of coexistence of stunting, underweight, and wasting was observed in West Africa $(3.11 \%)$ and the lowest prevalence in Southern Africa $(0.88 \%)$ (figure 2$)$.

Significant associations between all the independent variables and coexistence of stunting, wasting and underweight, except maternal age and age of household head, were identified (table 2).

\section{Risk factors of the coexistence of stunting, wasting, and underweight}

Table 3 shows the results of the multinomial regression analysis of the risk factors of coexistence of dimensions of undernutrition (stunting, underweight, and wasting) among children under 5 years in the SSA. Age of child, size of the child at birth, sex of the child, birth order, educational level, maternal age, antenatal care (ANC) attendance, place of delivery, source of drinking water, sex of household head, wealth index, access to electricity and place of residence were associated with one or two dimensions of undernutrition. See online supplemental appendix 3 for country-level risk of coexistence of stunting, wasting and underweight.

Regarding the coexistence of the three dimensions of undernutrition (stunting, underweight, and wasting), age of the child, sex of the child, perceived birth size, maternal educational attainment, working status, ANC visits during pregnancy, place of delivery, wealth status, access to media and type of toilet facility were found to be significant risk factors (table 3 ).

\section{DISCUSSION}

The study investigated the risk factors of the coexistence of stunting, underweight, and wasting among children under age 5 in SSA using data from DHS conducted in 31 countries between 2010 and 2019. The study found that the countries with the highest and lowest prevalence of coexistence of stunting, underweight and wasting were Benin and Gambia respectively. In terms of geographic region, the highest prevalence of coexistence of stunting, underweight and wasting was observed in Western Africa and the lowest prevalence in Southern Africa. The 
Table 2 Prevalence and association of the coexistence of stunting, underweight and wasting with independent variables

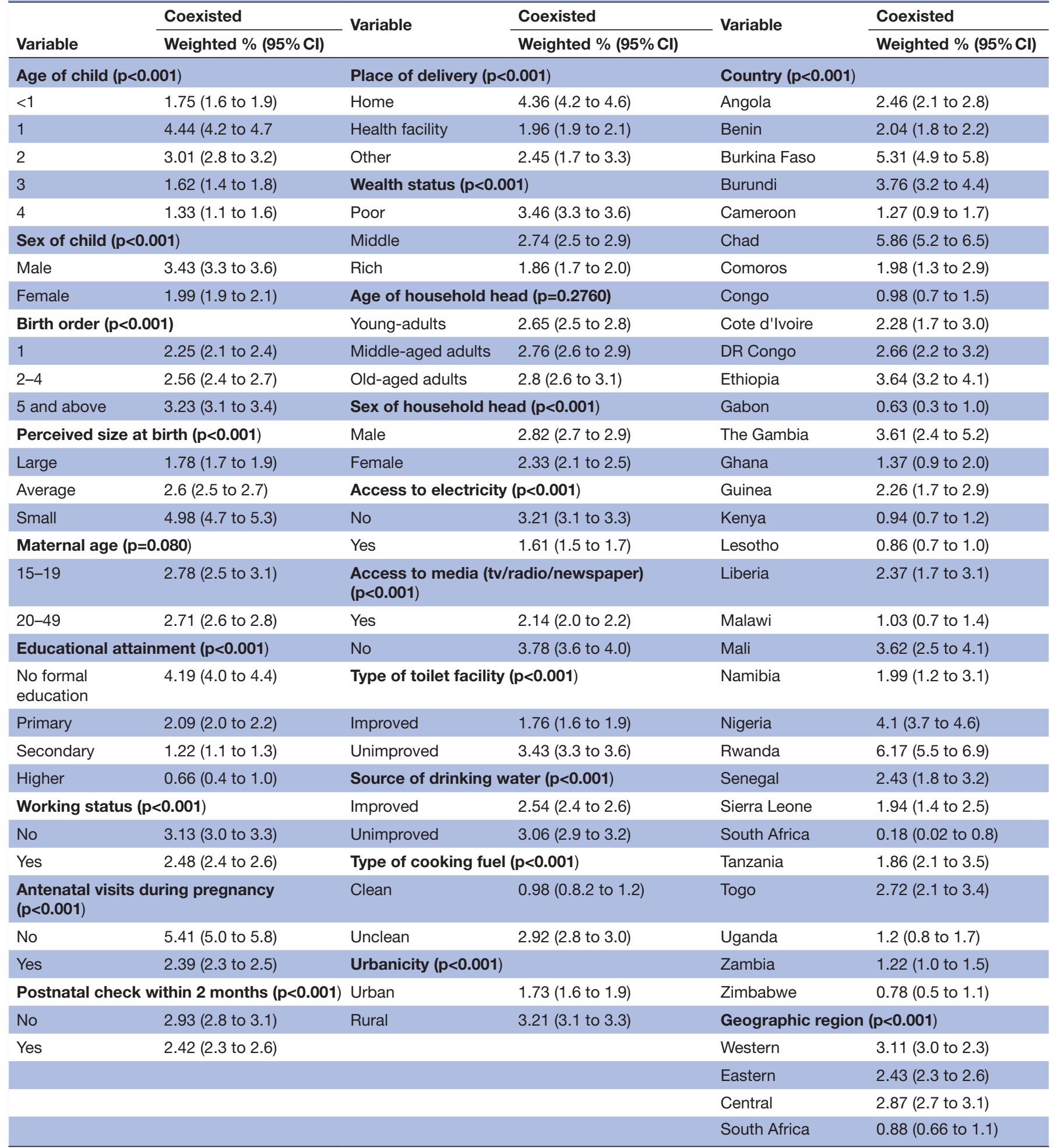

disparities in the prevalence among the countries and geographical regions could be attributed to differences in access to quality healthcare systems, nutritional practices, and beliefs practised in countries and the geographical regions. Differences in the health policies of governments in the various countries could also account for the disparities noted. This finding implies that countries that have high prevalence should take critical lessons from the countries that are doing well regarding the implementation of nutritional policies and interventions (eg, increasing dietary supplementation, increasing dietary diversity) that target the reduction of the coexistence of stunting, underweight and wasting among children under age 5 in SSA. ${ }^{2}$

Similar to previous studies, ${ }^{13}$ we found that children aged 1 year, 2 years and 3 years were at greater risk of 
Table 3 Multinomial regression showing risk factors of coexistence of stunting, underweight and wasting

\section{Base outcome (ref: normal)}

Single and two dimensions

Variable RRR

$95 \% \mathrm{Cl}$

Co-existence of three dimensions

Age of child (ref:0)

\begin{tabular}{|c|c|c|c|c|}
\hline 1 & $2.008^{\star \star \star}$ & 1.93 to 2.089 & $3.714^{\star \star \star}$ & 3.319 to 4.156 \\
\hline 2 & $2.624^{\star \star \star}$ & 2.514 to 2.739 & $2.827^{\star \star \star}$ & 2.48 to 3.222 \\
\hline 3 & $2.122^{\star \star \star}$ & 2.018 to 2.231 & $1.464^{\star \star \star}$ & 1.227 to 1.748 \\
\hline \multicolumn{5}{|c|}{ Sex of child (ref: male) } \\
\hline Female & $0.752^{\star \star \star}$ & 0.731 to 0.775 & $0.468^{* * *}$ & 0.429 to 0.51 \\
\hline
\end{tabular}

\section{Birth order (ref: 1)}

\begin{tabular}{|c|c|c|c|c|}
\hline 2 & $0.938^{\star *}$ & 0.896 to 0.981 & 1.002 & 0.875 to 1.146 \\
\hline five and above & 0.969 & 0.92 to 1.021 & 0.995 & 0.858 to 1.155 \\
\hline \multicolumn{5}{|c|}{ Perceived size at birth (ref: large) } \\
\hline Small & $1.931^{\star \star *}$ & 1.846 to 2.02 & $3.818^{* * *}$ & 3.383 to 4.308 \\
\hline \multicolumn{5}{|c|}{ Maternal age (ref: 15-19) } \\
\hline
\end{tabular}

\section{Educational attainment (ref: higher)}

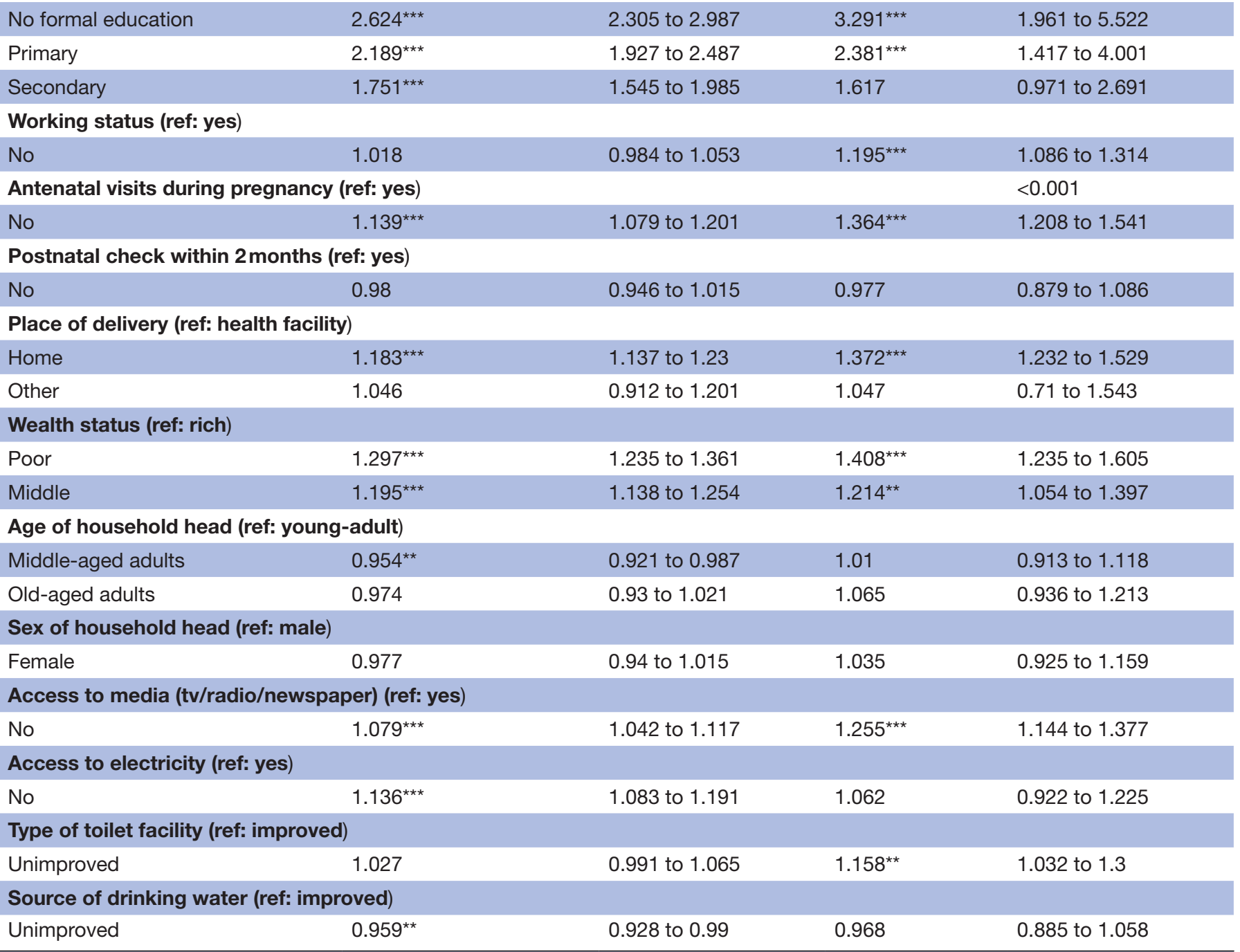




\begin{tabular}{|c|c|c|c|c|}
\hline \multirow[b]{3}{*}{ Variable } & \multicolumn{4}{|c|}{ Base outcome (ref: normal) } \\
\hline & \multicolumn{2}{|c|}{ Single and two dimensions } & \multicolumn{2}{|c|}{ Co-existence of three dimensions } \\
\hline & RRR & $95 \% \mathrm{Cl}$ & RRR & $95 \% \mathrm{Cl}$ \\
\hline Unclean & $1.177^{\star \star \star}$ & 1.089 to 1.271 & 1.316 & 0.97 to 1.787 \\
\hline \multicolumn{5}{|c|}{ Urbanicity (ref: urban) } \\
\hline
\end{tabular}

$R R R$, relative risk ratios.

having coexistence of all the three forms of undernutrition compared with those aged 0 . This could be as a result of the fact that as children grow their energy needs also increase $^{1}$ thereby increasing their risk of having all three nutritional conditions. Alternatively, since these nutritional conditions may manifest after long durations of improper nutritional practices or undernutrition, ${ }^{13}$ older children may be at higher risk of having all three nutritional conditions. The finding suggests that complementary foods given to children as they grow are inadequate. To reduce the risk of coexistence of stunting, underweight, and wasting among under 5 children, the health sectors in the various countries should invest heavily in providing adequate complementary feeding to this category of children.

Corroborating the findings of other studies, ${ }^{1} 3233$ this study also found that children who were females were less likely to have a coexistence of the three indicators of undernutrition compared with their male counterparts. This could be linked to biological variations in morbidity between males and females at that young age. ${ }^{3}$ Also, it is most likely that since male children have higher birth weight compared with females, they require more energy, ${ }^{134}$ which increases the risk of males having all three nutritional conditions. Moreover, male children are perceived to be hungrier than females, therefore, breastfeeding alone could be insufficient or inadequate, ${ }^{3} 35$ increasing their susceptibility to having the three nutritional conditions. The finding suggests that male children should be given more attention in the development and implementation of nutritional programmes (eg, dietary supplementation) to mitigate the coexistence of stunting, underweight, and wasting among these male children under 5 years.

Our findings further indicate that children of average to small size at birth were at higher risk of the coexistence of the three indicators of undernutrition compared with children of large size at birth. It has been proven that undernutrition in children is partly influenced by maternal nutrition lifestyle and practices. Hence, mothers' appropriate nutritional behaviours during the prenatal and postnatal periods are key to improving child growth. Conversely, maternal undernutrition causes low maternal BMI, which in turn affects the fetus leading to poor development often associated with a small birth size and low birth weight. ${ }^{132136}$ This finding indicates that mothers of children under 5 should continuously be educated on the best nutritional practices such as exclusive breastfeeding, complementary feeding and dietary supplementation. These strategies will help ameliorate the risk of acquiring health conditions associated with undernutrition among children under 5 .

The risk of coexistence of the three indicators was higher among children whose mothers had no education and primary education compared with those whose mothers had higher education. Mothers who have attained higher education are better informed about improved childcare practices, ${ }^{37}$ more empowered to make health decisions, ${ }^{38}$ practice good personal hygiene, ${ }^{38}$ more likely to use the health facility, ${ }^{39}$ proper feeding practices ${ }^{36}$ and childcare in times of illness. ${ }^{36}$ This finding suggests that mothers with no formal or little education are neglected in nutritional programmes that help to eliminate stunting, underweight and wasting. Hence, they should be given the needed consideration to deal with this persistent health issue.

The findings also revealed that the risk of coexistence of the three indicators of undernutrition was higher among children whose mothers were not working compared with those whose mothers were working. Women's employment status indicate, in part, their ability to afford proper nutritional products and healthcare services. ${ }^{36} 40$ Therefore, if mothers are not employed, the children become highly susceptible or vulnerable because mothers are unlikely to meet their nutritional needs or requirements. Mothers with children under 5 with such disadvantaged backgrounds should be given subsidies on children's nutritional products and perhaps, free access to healthcare services by governmental and non-governmental organisations. This step will be significant in reducing the risks of the coexistence of stunting, underweight and wasting among children under 5 years.

The risk of coexistence of the three dimensions was higher among children whose mothers had no antenatal visits during pregnancy compared with those whose mothers had antenatal visits during pregnancy. Specifically, mothers who attend antenatal services are usually educated on the best practices of nutrition and general healthcare, which hitherto would not be known by these mothers. ${ }^{38}$ Therefore, mothers who did not have 
antenatal visits may lack some knowledge about proper nutritional practices, increasing their children's risk of having these undernutrition-related challenges. Regular antenatal visits could reduce children's risk of stunting, being underweight, and wasting, therefore, mothers should continuously be encouraged to go for antenatal care services in their countries.

Children who were delivered at home compared with children who were delivered at a health facility were found to have a higher risk of coexistence of the three dimensions. Since mothers who deliver at home do not receive any expert nutritional advice from a qualified health practitioner, ${ }^{37}$ the children of such mothers are at higher risk of having these conditions because of poor and/ or inadequate dietary practices. This finding shows that facility delivery may help reduce the risk of coexistence of stunting, underweight and wasting among children under 5 . Therefore, mothers should regularly be educated on the need to opt for facility delivery because of its positive implications on children's growth.

The risk of coexistence of the three indicators was higher among children whose mothers were poor and had middle wealth status compared with those whose mothers were rich. Usually, mothers who have an average income may lack the financial capacity to feed themselves and their children properly and adequately, ${ }^{3} 1736$ increasing the children's risk of being stunted, underweight or wasted. Likewise, mothers from poor and middle wealth quintiles may not have access to quality nutritional products and healthcare systems, ${ }^{36} 40$ making their children more susceptible to having all three nutritional conditions. This finding implies that women from poor economic backgrounds should be assisted with nutritional products and services to facilitate the reduction in the risks of the coexistence of stunting, underweight, and wasting among children under 5 .

It was also found that the risk of coexistence of the three indicators was higher among children whose mothers had no access to media compared with those whose mothers had access to media. Since many people are educated about proper nutritional practices through the mass media, ${ }^{10} 11$ mothers who have no access to the media may lack certain important nutritional information they need. This information gap could increase children's risk of having all three nutritional conditions through improper dietary practices from their mothers. For instance, mothers' access to appropriate information from the media would help them decide on which proper diets or food commodities are readily available on market for their children. More pragmatic ways of reaching mothers who have no access to media are encouraged. Regular outreach or sensitisation programmes to target women without access to media for example could help in reducing the risks of the coexistence of stunting, underweight and wasting among children under 5 years.
Children whose mothers lived in households with unimproved toilet facilities were found to have a higher risk of coexistence of the three indicators of child undernutrition compared with those whose mothers had improved toilet facilities. Insanitary or unhygienic toilet conditions may increase mother-child-environment interactions that may result in increased exposure to childhood diseases and other opportunistic infections (eg, diarrhoeal episodes, fever) either through consumption of contaminated foods, drinking water or poor environmental sanitation. ${ }^{21}$ These conditions are known causes of growth retardation in children. Government and non-governmental organisations should support the provision of improved household toilet facilities for poorer communities to help minimise the risks of the coexistence of child undernutrition indicators.

Children from Burkina Faso, Burundi, Chad, Nigeria and Rwanda had a higher risk of having the coexistence of the three dimensions compared with those from Angola. On the other hand, countries such as Benin, Cameroon, Congo, Gabon, Ghana, Guinea, Kenya, Lesotho, Malawi, Senegal, Zambia, Uganda, Tanzania, Sierra Leone, Zimbabwe and South Africa had a lower risk among their children having coexistence of the three undernutrition dimensions. The subregional and country-specific variations in access to quality healthcare systems, socioeconomic conditions, agroecological and geographical characteristics may strongly influence the nutritional status of children because of inadequate food supplies, limited access to arable land for agriculture, unfavourable climatic conditions (eg, desertification), rapid population growth and increasing cost of living may determine food access, availability and production in studied countries in SSA. ${ }^{41}{ }^{42}$ Governmental priorities should intensify efforts to minimise the risk of coexistence of stunting, underweight and wasting among children under age 5 with sound socioeconomic and sustainable human capital development.

\section{Strength and limitations}

The use of relatively large nationally representative data of under- 5 children from 31 countries in SSA is the main strength of the study. We also employed rigorous statistical analytical techniques to analyse the data. A broad range of potential risk factors at various levels were considered in our analysis. Despite these, the DHS employs cross-sectional designs which restrict causality on the noted outcomes. Self-reported variables used are susceptible to biases from recall and other social desirability issues. The surveys were also conducted in different years.

\section{CONCLUSIONS AND IMPLICATIONS}

The study found that the prevalence of coexistence of stunting, underweight and wasting ranged from $0.58 \%$ in the Gambia to $12.14 \%$ in Benin. It was also found 
that the prevalence of coexistence of stunting, underweight and wasting was high in West Africa (41.78\%) but low in Southern Africa (5.3\%). The significant findings show that the disadvantaged have more risks of the coexistence of stunting, underweight and wasting among under 5 children in selected countries in SSA. These findings demonstrate the urgent need for consideration of the coexistence of stunting, wasting and underweight among under-5 children in policy design and programming of interventions to eradicate child undernutrition in SSA. In the short-term, nationallevel policies and interventions need to be well tailored considering the compositional characteristics including child's age, sex, birth size, maternal education, working status, place of delivery, ANC visit, and household's wealth status, access to media and improved toilet facility are required. For instance, such programmes could be geared towards improving females' access to education, reducing unemployment, expanding access to the media and using it to promote education on the need for ANC. In the long term, regional policies and coordinated interventions among governments of SSA countries need to be designed to address the disparate prevalence of the coexistence of stunting, wasting, and underweight in under- 5 children across the four geographic regions. The implementation of these at the local level should consider rural-urban differences in the prevalence of the condition and the risk factors elicited.

\section{Author affiliations}

${ }^{1}$ Africa Centre of Excellence in Coastal Resilience, University of Cape Coast, Cape Coast, Ghana

${ }^{2}$ Department of Fisheries and Aquatic Sciences, School of Biological Sciences, College of Agriculture and Natural Sciences, University of Cape Coast, Cape Coast, Ghana

${ }^{3}$ Emperiks Research, Tamale, Ghana

${ }^{4}$ Department of Estate Management, Takoradi Technical University, Takoradi, Ghana ${ }^{5}$ College of Public Health, Medical and Veterinary Sciences, James Cook University, Townsville, Queensland, Australia

${ }^{6}$ Centre for Gender and Advocacy, Takoradi Technical University, Takoradi, Ghana ${ }^{7}$ Department of Health, Physical Education, and Recreation, University of Cape Coast, Cape Coast, Central, Ghana

${ }^{8}$ Neurocognition and Action-Biomechanics-Research Group, Faculty of Psychology and Sports Science, Bielefeld University, Bielefeld, Germany

${ }^{9}$ Department of Family and Community Health, School of Public Health, University of Health and Allied Sciences, Hohoe, Ghana

${ }^{10}$ Department of Academics, Nursing and Midwifery Training College, Esiama, Ghana

${ }^{11}$ Department of Health Promotion, Education and Disability Studies, Kwame

Nkrumah University of Science and Technology, Kumasi, Ghana

${ }^{12}$ School of Public Health, Faculty of Health, University of Technology Sydney, Sydney, Ultimo NSW, Australia

Acknowledgements The authors thank the MEASURE DHS project for their support and free access to the original data.

Contributors IA and BOA developed the study concept. IA performed the data analysis. A-AS, ED, JBF, JEH, RGA, BA, CA and BOA drafted and revised the manuscript critically for its intellectual content. All authors read and approved the final manuscript. A-AS had the final responsibility to submit the manuscript. A-AS is acting as guanrantor.

Funding The authors have not declared a specific grant for this research from any funding agency in the public, commercial or not-for-profit sectors.
Map disclaimer The inclusion of any map (including the depiction of any boundaries therein), or of any geographic or locational reference, does not imply the expression of any opinion whatsoever on the part of BMJ concerning the legal status of any country, territory, jurisdiction or area or of its authorities. Any such expression remains solely that of the relevant source and is not endorsed by BMJ. Maps are provided without any warranty of any kind, either express or implied.

Competing interests None declared.

Patient consent for publication Not required.

Ethics approval This study used secondary data from the DHS Program. Since we neither interacted directly nor indirectly with the study participants, there was no need for ethical approval. Details on the ethical considerations of the DHS Program could be found at https://dhsprogram.com/methodology/Protecting-the-Privacy-ofDHS-Survey-Respondents.cfm

Provenance and peer review Not commissioned; externally peer reviewed.

Data availability statement Data are available in a public, open access repository. The dataset is available at https://dhsprogram.com/data/available-datasets.cfm

Supplemental material This content has been supplied by the author(s). It has not been vetted by BMJ Publishing Group Limited (BMJ) and may not have been peer-reviewed. Any opinions or recommendations discussed are solely those of the author(s) and are not endorsed by BMJ. BMJ disclaims all liability and responsibility arising from any reliance placed on the content. Where the content includes any translated material, BMJ does not warrant the accuracy and reliability of the translations (including but not limited to local regulations, clinical guidelines, terminology, drug names and drug dosages), and is not responsible for any error and/or omissions arising from translation and adaptation or otherwise.

Open access This is an open access article distributed in accordance with the Creative Commons Attribution Non Commercial (CC BY-NC 4.0) license, which permits others to distribute, remix, adapt, build upon this work non-commercially, and license their derivative works on different terms, provided the original work is properly cited, appropriate credit is given, any changes made indicated, and the use is non-commercial. See: http://creativecommons.org/licenses/by-nc/4.0/.

\section{ORCID iDs}

Iddrisu Amadu http://orcid.org/0000-0003-4839-1197

Abdul-Aziz Seidu http://orcid.org/0000-0001-9734-9054

Eric Duku http://orcid.org/0000-0003-4914-0445

James Boadu Frimpong http://orcid.org/0000-0002-9416-1176

John Elvis Hagan Jnr. http://orcid.org/0000-0003-3530-6133

Bright Opoku Ahinkorah http://orcid.org/0000-0001-7415-895X

\section{REFERENCES}

1 Amare ZY, Ahmed ME, Mehari AB. Determinants of nutritional status among children under age 5 in Ethiopia: further analysis of the 2016 Ethiopia demographic and health survey. Global Health 2019;15:1-11.

2 Anin SK, Saaka M, Fischer F, et al. Association between infant and young child feeding (IYCF) indicators and the nutritional status of children (6-23 months) in northern Ghana. Nutrients 2020;12:2565.

3 Madiba S, Chelule PK, Mokgatle MM. Attending informal preschools and daycare centers is a risk factor for underweight, stunting and wasting in children under the age of five years in underprivileged communities in South Africa. Int J Environ Res Public Health 2019;16:2589.

$4 \mathrm{M}$ yalew B, Amsalu F, Bikes D. Prevalence and factors associated with stunting, underweight and wasting: a community based cross sectional study among children age 6-59 months at Lalibela town, Northern Ethiopia. J Nutr Disorders Ther 2014;04:2161-509.

5 WHO. Nutrition landscape information system (NLIS) country profile indicators: interpretation guide. Geneva, Switzerland: World Health Organization, 2010.

6 Akombi B, Agho K, Hall J, et al. Stunting, wasting and underweight in sub-Saharan Africa: a systematic review. Int J Environ Res Public Health 2017;14:863.

7 WHO. Global nutrition targets 2025: policy brief series (WHO/NMH/ NHD/14.2). Geneva: World Health Organization, 2014. https://apps. who.int/iris/bitstream/handle/10665/149018/WHO_NMH_NHD_14.2_ eng.pdf

8 Black RE, Victora CG, Walker SP, et al. Maternal and child undernutrition and overweight in low-income and middle-income countries. Lancet 2013;382:427-51. 
9 World Health Organization. Levels and trends in child malnutrition: key findings of the 2019 edition (No. WHO/NMH/NHD/19.20). World Health Organization, 2019.

10 de Onis M, Onyango A, Borghi E, et al. Worldwide implementation of the WHO child growth standards. Public Health Nutr 2012;15:1603-10.

11 de Onis M, Blössner M, Borghi E. Prevalence and trends of stunting among pre-school children, 1990-2020. Public Health Nutr 2012;15:142-8.

12 World Health Organization. Community-based management of severe acute malnutrition: a joint statement by the World Health Organization, the World Food Programme, the United Nations System Standing Committee on Nutrition and the United Nations Children's Fund, 2007

13 UNICEF. Levels and trends in child malnutrition, United Nations Children's fund (UNICEF), World Health Organization, International Bank for Reconstruction and Development/The World Bank. Levels and trends in child malnutrition: key findings of the 2019 edition of the joint child malnutrition estimates. Geneva: World Health Organization, 2019.

14 Central Statistical Agency (CSA)[Ethiopia] and ICF. Ethiopia demographic and health survey, Addis Ababa, Ethiopia and Calverton, Maryland, USA, 2016.

15 Yaya S, Uthman OA, Ekholuenetale M, et al. Effects of birth spacing on adverse childhood health outcomes: evidence from 34 countries in sub-Saharan Africa. J Matern Fetal Neonatal Med 2020;33:3501-8.

16 Armah FA, Ekumah B, Yawson DO, et al. Predictive probabilities of access to clean cooking: evidence from the demographic and health surveys in 31 countries in sub-Saharan Africa. Environ Justice 2019;12:118-31.

17 Mamabolo RL, Alberts M, Steyn NP, et al. Prevalence and determinants of stunting and overweight in 3-year-old black South African children residing in the central region of Limpopo Province, South Africa. Public Health Nutr 2005;8:501-8.

18 Novignon J, Aboagye E, Agyemang OS, et al. Socioeconomic-related inequalities in child malnutrition: evidence from the Ghana multiple indicator cluster survey. Health Econ Rev 2015;5:1-11.

19 Khara T, Mwangome M, Ngari M, et al. Children concurrently wasted and stunted: A meta-analysis of prevalence data of children 6-59 months from 84 countries. Matern Child Nutr 2018;14:e12516.

20 Boah M, Azupogo F, Amporfro DA, et al. The epidemiology of undernutrition and its determinants in children under five years in Ghana. PLoS One 2019;14:e0219665.

21 Khan REA, Raza MA. Determinants of malnutrition in Indian children: new evidence from IDHS through CIAF. Qual Quant 2016;50:299-316.

22 Angood C, Khara T, Dolan C, et al. Research priorities on the relationship between wasting and stunting. PLoS One 2016;11:e0153221.

23 Corsi DJ, Neuman M, Finlay JE, et al. Demographic and health surveys: a profile. Int J Epidemiol 2012;41:1602-13.

24 Aliaga A, Ruilin R. Cluster optimal sample size for demographic and health surveys. 7th International Conference on Teaching StatisticsICOTS, 2006:2-7.
25 DHS. DHS data source. Available: https://dhsprogram.com/data/ available-datasets.cfm

26 von Elm E, Altman DG, Egger M, et al. The strengthening the reporting of observational studies in epidemiology (STROBE) statement: guidelines for reporting observational studies. Int J Surg 2014;12:1495-9.

27 Collins J, Ward BM, Snow P, et al. Compositional, contextual, and collective community factors in mental health and well-being in Australian rural communities. Qual Health Res 2017;27:677-87.

28 Pol LG, Thomas RK. The demography of health and health care. Springer Science \& Business Media, 2001.

29 Armah FA, Ekumah B, Yawson DO, et al. Access to improved water and sanitation in sub-Saharan Africa in a quarter century. Heliyon 2018;4:e00931.

30 Ross CE, Mirowsky J. Neighborhood socioeconomic status and health: context or composition? City Community 2008;7:163-79.

31 Amegah AK, Boachie J, Näyhä S, et al. Association of biomass fuel use with reduced body weight of adult Ghanaian women. J Expo Sci Environ Epidemiol 2020;30:670-9.

32 Alemayehu M, Tinsae F, Haileslassie K, et al. Undernutrition status and associated factors in under- 5 children, in Tigray, Northern Ethiopia. Nutrition 2015;31:964-70.

33 Mya KS, Kyaw AT, Tun T. Feeding practices and nutritional status of children age 6-23 months in Myanmar: a secondary analysis of the 2015-16 demographic and health survey. PLoS One 2019;14:e0209044.

34 Bork KA, Diallo A. Boys are more stunted than girls from early infancy to 3 years of age in rural Senegal. J Nutr 2017;147:940-7.

35 Tumilowicz A, Habicht J-P, Pelto G, et al. Gender perceptions predict sex differences in growth patterns of Indigenous Guatemalan infants and young children. Am J Clin Nutr 2015;102:1249-58.

36 Mukabutera A, Thomson DR, Hedt-Gauthier BL, et al. Risk factors associated with underweight status in children under five: an analysis of the 2010 Rwanda demographic health survey (RDHS). BMC Nutr 2016;2:1-12.

37 Oyekale AS. Factors explaining acute malnutrition among under-five children in Sub-Sahara Africa (SSA). Life Sci J 2012;9:2101-7.

38 Keats A. Women's schooling, fertility, and child health outcomes: Evidence from Uganda's free primary education program. J Dev Econ 2018;135:142-59.

39 Sunguya BF, Poudel KC, Mlunde LB, et al. Poor nutrition status and associated feeding practices among HIV-positive children in a food secure region in Tanzania: a call for tailored nutrition training. PLoS One 2014;9:e98308.

40 lannotti LL, Dulience SJL, Green J, et al. Linear growth increased in young children in an urban slum of Haiti: a randomized controlled trial of a lipid-based nutrient supplement. Am J Clin Nutr 2014;99:198-208.

41 Lopriore C, Muehlhoff E. Food security and nutrition trends in West Africa-Challenges and the way forward. Proceedings of the 2 nd International Workshop on Food-based Approaches for a Healthy Nutrition, Ouagadougou, Burkina, 2003:23-8.

42 Salami A, Kamara AB, Brixiova Z. Smallholder agriculture in East Africa: trends, constraints and opportunities. Tunis, Tunisia: African Development Bank, 2010. 